\title{
A FORMAÇÃO INICIAL DO PROFESSOR DE LÍNGUA PORTUGUESA E A ELABORAÇÃO DIDÁTICA DOS CONTEÚDOS DE ENSINO: O CASO DE UMA UNIVERSIDADE NO VALE DO ITAJAÍ
}

\author{
INITIAL TRAINING OF PORTUGUESE TEACHERS AND DIDACTIC ELABORATION OF TEACHING \\ CONTENTS: THE CASE OF A UNIVERSITY IN THE ITAJAÍ VALLEY
}

\author{
Ana Paula Kuczmynda da Silveira* \\ Instituto Federal de Educação, Ciência e Tecnologia de Santa Catarina - IFSC, Gaspar, BR \\ Universidade Federal de Santa Catarina - UFSC, Florinanópolis, BR
}

\begin{abstract}
RESUMO: Este artigo tem escopo sobre a elaboração didática da noção de gênero do discurso para as práticas de ensino e aprendizagem de leitura/escuta, produção textual e análise linguística que se depreende dos relatórios e projetos de estágio supervisionado produzidos por acadêmicos em fase final da formação inicial no contexto do Curso de Graduação em Letras Inglês/Português de uma universidade situada na região do Vale do Itajaí (SC). A pesquisa envolveu a análise de 40 documentos de estágio elaborados entre o primeiro semestre de 2002 e o segundo semestre de 2008, período este que envolve a transição entre duas grades curriculares do referido curso. Na vigência da primeira grade estudada, prepondera uma preocupação classificatória (classificação de textos quanto ao gênero) e o trabalho norteado pela tipologia escolar clássica. Na vigência da segunda grade, ainda que muitas vezes os gêneros não sejam efetivamente alvo de elaboração didática, depreendemos uma perspectiva de mudança, verificada na preocupação em se pesquisar sobre o gênero a ser trabalhado; na busca por oportunizar ao aluno desenvolver um conhecimento procedimental do gênero e na articulação entre práticas de leitura e produção textual.

PALAVRAS-CHAVE: gêneros do discurso; elaboração didática; leitura/escuta; produção textual; análise linguística.
\end{abstract}

ABSTRACT: This paper focuses on the didactic elaboration of the notion of speech genres for learning and teaching practices involving reading/listening, writing and linguistics analysis, which emerged from supervised training projects and reports produced by undergraduate students in the end of their initial training within the context of an English/Portuguese Undergraduate Course of Modern Languages from an university located in the region of Itajaí Valley (Santa Catarina, Brazil). This research comprised the analysis of 40 training documents produced from the first semester of 2002 until the second semester of 2008. This period covers the transition between two curricular frameworks of the researched course. Within the first curricular framework, there was a remarkable concern about classifying texts according to the genre they belonged to and work was frequently guided by the classic school typology of texts (narration, description and dissertation). Within the second curricular framework, although speech genres are not often object of didactic elaboration in efect, we observed a perspective of change that may be verified in the concern about researching the speech genre with which the undergraduate student will work, and about trying to enable the student to acquire a procedimental knowledge about the genre in the articulation between reading and writing practices.

KEYWORDS: speech genres; didactic elaboration; reading/listening; writing; linguistic analysis.

\section{INTRODUÇÃO}

Este artigo representa um recorte de minha dissertação de mestrado, defendida no final de 2009, na Universidade Federal de Santa Catarina, a qual constituiu um estudo de caso e teve como objetivo realizar uma análise interpretativo-comparativa, de base enunciativo-discursiva, do discurso do professor em fase final formação, no contexto do Curso de Graduação em Letras Inglês/Português (licenciatura) de uma universidade situada no Vale do Itajaí (SC) no que tange à elaboração do referencial teórico e à elaboração didática da noção de gênero do discurso para as práticas de ensino-aprendizagem de leitura, escuta, escrita e análise linguística na vigência de duas grades curriculares: a que vigorou entre o segundo semestre de 1998 e o último semestre de 2003, e a grade curricular que entrou em vigor no primeiro semestre de 2004 (SILVEIRA, 2008).

É relevante mencionar que entendemos que a transição entre tais grades curriculares ocorreu inserida no bojo de outras muitas mudanças que se operaram na universidade; no corpo docente; nos discursos, 
diretrizes e parâmetros teórico-metodológicos que permeiam as esferas escolar e científica e, portanto, a área acadêmica. Apesar de a teoria sócio-dialógica do Círculo de Bakhtin ser estudada no Brasil desde a década de 1980 - tendo norteado a elaboração da PC-SC, que teve sua primeira versão publicada no final dos anos 1980, início dos anos 1990, e dos PCN, publicados no final de década de 1990 -, é a partir das mudanças levadas a efeito na grade curricular do curso em questão, no primeiro semestre de 2004, que se abre espaço para inserção do gênero do discurso como conteúdo didático-pedagógico nas disciplinas voltadas à formação do professor, as quais compõem parte das ementas e planos de ensino do Curso de graduação em Letras Inglês/Português (licenciatura) da FURB. Estimamos que tal inserção abra espaço para uma discussão de ordem teórico-metodológica acerca dos gêneros do discurso no contexto da formação inicial; entretanto, até que ponto essa inserção ocorreu de fato e a que resultados efetivos levou no que tange à elaboração didática dos gêneros do discurso para a prática de leitura/escuta, produção textual e análise linguística no âmbito das atividades de estágio de docência dos acadêmicos em fase final de formação inicial? Essa, a pergunta que nos inquietou e nos levou ao desenvolvimento da presente pesquisa.

Nesse contexto, foi a percepção de que os gêneros agem como baliza no ato da leitura/escuta e da produção de textos, ratificam papéis sociais no âmbito das esferas que permeiam, materializam necessidades discursivas destas esferas e dos sujeitos que nelas interagem e são horizontes/índices de produção dos sentidos dos enunciados (BAKHTIN, 2003b [1975]), que nos fez crer na pertinência de pesquisar o modo como se dá sua elaboração didática (dos gêneros) para a prática de leitura/escuta, produção textual e análise linguística na esfera escolar.

Constituíram referência central de pesquisa as obras do Círculo de Bakhtin, as quais balizaram nossas apreensões de sujeito como socio-historicamente situado; da realidade dialógica da linguagem; de texto entendido como enunciado e de gêneros do discurso (2003a [1975], 2003b [1975], 2003c [1975]). Ao pensarmos a interação que se dá no espaço da sala de aula, somaram-se às vozes do Círculo de Bakhtin, outras vozes, dentre as quais realçamos as de Geraldi (1984, 2002 [1991]), Franchi (1987), Britto (2002), Halté (1998) e Petitjean (1998), que nos fizeram refletir sobre a pertinência do trabalho com o texto sob uma perspectiva linguística e epilinguística e sobre a noção de elaboração didática.

Este artigo está organizado em quatro seções: na primeira, explicitamos a constituição dos dados de pesquisa; na segunda, refletimos sobre a noção de elaboração didática e sua articulação com o ensino de língua portuguesa; na terceira, analisamos alguns dados de pesquisa à luz das contribuições do Círculo de Bakhtin para se pensar língua, texto/enunciado e gênero do discurso; e na quarta e última seção apresentamos nossas considerações finais de pesquisa.

\section{A CONSTITUIÇÃO DOS DADOS DE PESQUISA}

As atividades de estágio supervisionado, no âmbito da primeira grade curricular estudada (a grade que entrou em vigor no segundo semestre de 1998, doravante denominada grade 1998/2), concentravam-se nos dois últimos semestres do curso de Letras $\left(7^{\circ}\right.$. e $8^{\circ}$. semestres), vinculando-se às disciplinas Prática de Ensino da Língua Portuguesa I e II. No sétimo semestre, estavam concentradas as atividades de observação e, no oitavo semestre, as atividades de docência. A primeira turma da grade 1998/2 concluiu o curso no primeiro semestre de 2002 e a última turma dessa grade o concluiu (o curso) no primeiro semestre de 2007, razão pela qual, no âmbito dessa grade, a análise contemplou relatórios e projetos de estágio elaborados nesse período.

Já no âmbito da grade curricular que entrou em vigor no primeiro semestre de 2004 (doravante denominada grade 2004/1), as atividades de estágio distribuem-se ao longo dos quatro últimos semestres do curso $\left(5^{\circ} ., 6^{\circ}\right.$., $7^{\circ}$. e $8^{\circ}$. semestres), correspondendo às disciplinas Estágio Curricular de Língua Portuguesa I, II, III e IV. Os dois primeiros semestres destinam-se à realização de atividades de observação 
em campo de estágio, o terceiro a atividades de observação e docência no ensino fundamental e o quarto a atividades de observação e docência no ensino médio. A primeira turma da grade 2004/1 a concluir o curso o fez no segundo semestre de 2007, o que nos levou a trabalhar com relatórios analíticos de estágio supervisionado elaborados entre o segundo semestre de 2007 e o segundo semestre de 2008, época em que a pesquisa foi realizada.

Portanto, os dados da pesquisa são constituídos por projetos e relatórios de estágio elaborados entre o primeiro semestre de 2002 e o segundo semestre de 2008. Partimos de dados provenientes de 21 projetos de estágio supervisionado e 35 relatórios de estágio supervisionado elaborados entre o primeiro semestre de 2002 e o primeiro semestre de 2007 (inclusive) $^{1}$; e 22 relatórios analíticos de estágio supervisionado elaborados a partir do segundo semestre de $2007^{2}$. Dentre esses, selecionamos para proceder à análise 8 projetos e 15 relatórios de estágio supervisionado; e 17 relatórios analíticos de estágio supervisionado; totalizando 40 documentos de estágio elaborados entre o primeiro semestre de 2002 e o segundo semestre de 2008. A seleção dos dados atendeu a dois critérios: conteúdo abordado - gêneros do discurso; contex to majoritário de realização das atividades de observação e docência em turmas de ensino fundamental.

Faz-se necessário esclarecer aqui que os dados mencionados ao longo do artigo são identificados da seguinte forma: as letras $\mathrm{R}, \mathrm{P}$ ou RA identificam a fonte de cada excerto - relatórios (R), projetos de estágio (P) e relatórios analíticos (RA) - sendo seguidas por números que identificam o relatório, projeto ou relatório analítico do qual provêm os dados entre aqueles selecionados e o ano de elaboração do documento. Assim, R3-2006 faz referência a um trecho citado do relatório número 1 de 2006; RA 1-2008 faz referência a um trecho citado do relatório analítico número 1 de 2008, e assim por diante.

A análise foi realizada em duas etapas que envolveram: (1) a análise do capítulo destinado à fundamentação teórica das atividades de estágio de docência, capítulo esse presente nos projetos de estágio da grade 1998/2 e nos relatórios analíticos de estágio supervisionado da grade 2004/1; (2) a análise dos planos de aula e relatos de aulas ministradas durante o período de estágio supervisionado no contexto do ensino fundamental, informações essas contidas nos relatórios de estágio supervisionado da grade 1998/2 e nos relatórios analíticos de estágio supervisionado da grade 2004/1. Para este artigo, interessam-nos os dados relativos à análise dos planos de aula e relatos de aulas ministradas como parte das atividades de estágio de docência.

Para chegar à elaboração didática dos gêneros do discurso foi necessário percorrer um caminho bastante amplo, o qual foi se configurando à medida que nos aprofundávamos no caso. Situamos primeiramente a universidade e, consequentemente, o Curso de graduação em Letras Inglês/Português (licenciatura) dessa mesma universidade, os professores de ensino superior a ele vinculados e os acadêmicos que nesse espaço vão se constituindo professores, no âmbito da área acadêmica, a qual se constitui, como já dito, na intersecção entre as esferas científica e educacional. Situar a formação inicial do professor nas fronteiras de tais esferas significa entendê-la atravessada pelos discursos que aí circulam e são produzidos, os quais, por sua vez, inscrevem-se em uma sócio-historicidade que remete: (1) à história da disciplina de Língua Portuguesa (no contexto da educação básica), seus objetos de ensino e os pressupostos teóricometodológicos que os ancoram; (2) à história da formação do professor de educação básica. Significa, também, perceber que tanto o discurso dos professores de ensino superior, quanto o discurso do acadêmico em fase final de formação, representam uma reação-resposta ativa a tais discursos, com os quais dialogam, uma vez que todo pensamento nasce do pensamento do outro e representa a apreensão deste mesmo

\footnotetext{
${ }^{1}$ É importante assinalar que esses números não se referem ao número total de projetos e relatórios produzidos nesse período, mas ao total de projetos e relatórios aos quais tivemos acesso, ou seja, que se encontravam disponíveis para consulta no Centro de Memória Universitária da universidade em que a pesquisa foi realizada. Por vezes, ainda, tivemos acesso ao relatório, mas não ao projeto que lhe era correspondente. Acreditamos que o ideal seria trabalhar sempre com o par projeto-relatório, porém, nesse caso, ficaríamos sem quaisquer registros de trabalhos realizados em alguns semestres. Outrossim, não conseguimos acesso a relatórios e projetos elaborados ao longo de 2003 , motivo pelo qual eles não compõem os dados da pesquisa.

${ }^{2}$ Esse número corresponde efetivamente ao número total de relatórios analíticos de estágio supervisionado produzidos nesse período.
} 
pensamento sob um ponto de vista axiológico (VOLOSHINOV/BAKHTIN, 2004), o qual coaduna com as representações sócio-histórico-ideológicas nas quais o indivíduo se constitui como sujeito.

Nesse sentido, estudar os textos dos acadêmicos em fase final de formação, mais especificamente, estudar os registros realizados por estes sujeitos nos relatórios e projetos de estágio supervisionado, permite-nos entrevê-los enquanto sujeitos inscritos na área acadêmica, intrumentalizando-nos para perceber dados que remetem à formação desses acadêmicos ao longo do curso de graduação e, mesmo, aos discursos que permeiam esse contexto específico de formação.

Bakhtin (2003c) sugere o texto, na modalidade oral ou escrita, ou materializado em outro material semiótico, como "dado primário" das disciplinas da área filosófico-humanista devido a sua capacidade de expressar a realidade do pensamento e da emoção. Ressalta que todo pensamento nasce do pensamento do outro e representa a apreensão deste mesmo pensamento sob um ponto de vista axiológico particular (VOLOSHINOV/BAKHTIN, 2004), que coaduna com as representações sócio-histórico-ideológicas nas quais o indivíduo se constitui como sujeito. Portanto, ao analisarmos o texto do outro, nós o entrevemos imerso em uma rede de relações dialógicas que o permeiam e o atravessam, firmando-se sobre dois pilares: o sistema da língua, que corresponde àquilo que é reproduzível e repetível na dimensão textual (historicidade), e o enunciado, que remete à irreprodutibilidade, unicidade e individualidade de cada texto (acontecimento) (BAKHTIN, 2003c).

\section{DA TRANSPOSIÇÃO À ELABORAÇÃO DIDÁTICA DOS CONTEÚDOS DE ENSINO}

O início da década de 80 do século XX foi assinalado por um discurso de constatação da crise que se instalou na educação brasileira, verificada no baixo desempenho linguístico dos alunos tanto na modalidade oral, quanto na modalidade escrita, e por um discurso de mudança. Geraldi (2002, p. 2) menciona que esse discurso ganhou as páginas dos jornais "não como [relato de] acontecimentos extraordinários, mas como emergência de acontecimentos cotidianos.”. Esse discurso de mudança era permeado, por um lado, pela ideia de educação com qualidade (VERMON, 2004), slogan que atendeu aos imperativos de modernização da escola e dos conteúdos curriculares para que essa (a escola) desse conta das competências requeridas por uma realidade econômica cada vez mais complexa e dinâmica, e, por outro lado, por uma discussão acirrada a respeito de novas orientações teórico-metodológicas para o ensino da língua.

Britto (2002) afirma que, em um primeiro momento, as críticas ao ensino da língua se centralizaram na percepção de que o ensino era "descontextualizado e autoritário" e se concentravam mais no modo de ensinar do que nos conteúdos a serem ensinados, dando valor especial à criatividade do aluno. De fato, a crítica ao ensino da língua ganha maior consistência a partir do fim da década de setenta e ao longo dos anos oitenta. Esse momento foi assinalado pela força que começavam a ganhar, no Brasil, os estudos linguísticos em campos como a Análise do Discurso, a Pragmática, a Linguística Aplicada, a Linguistica Textual, a Psicolinguistica e a Teoria da Enunciação, pelas extensivas críticas ao ensino tradicional da gramática, encetado sob uma perspectiva metalinguística e prescritiva, e pelo impacto de estudos realizados a respeito dos hábitos e processos de leitura. Ficou evidente uma incerteza, ou melhor, uma divisão por parte dos professores de Língua Portuguesa, a respeito da melhor abordagem para o ensino da língua, já que as abordagens utilizadas até então, tanto a tradicional, quanto aquela baseada na Teoria da Comunicação, não vinham dando resultados, o que era facilmente observável a partir da análise das provas de vestibulares da época.

As críticas ao ensino da gramática, ponto principal de apoio do ensino tradicional da língua, voltaram-se tanto a aspectos teóricos relativos "aos erros e inadequações das teorias a ela subjacentes", como a aspectos metodológicos: "sua forma de apresentação e a utilidade dos conceitos e valores oferecidos ao aluno" (BRITTO, 2002, p.102). As reflexões que tomaram lugar nessa época motivaram uma reconfiguração do ensino da língua materna no que tange a seus objetivos, conteúdos, pressupostos teóricos e metodológicos, 
despertando discussões acerca da questão das variantes linguísticas e ensino da variante padrão, das práticas de leitura e de produção textual (ÂNGELO, 2005).

Como aponta Britto (2002), a escola havia abandonado o texto e o movimento necessário de trazê-lo de volta ao contexto da sala de aula implicava pensar a língua em uso. A crítica renovadora que ganhou força nessa época apontava os problemas que tornavam o ensino tradicional ineficaz: (1) a indefinição a respeito do ato de ensinar; (2) a valorização preponderante da norma culta e da escrita e a insistência na abordagem das exceções em detrimento às regularidades da norma; (3) o enfoque descontextualizado e carente de sentido da leitura e produção textual; (4) a inconsistência e afastamento da realidade percebidos na teoria gramatical que servia de base às gramáticas escolares; (5) o mecanicismo das atividades conectadas à abordagem gramatical que se atrelavam mais à aquisição de uma metaliguagem do que à proposta de análise linguística (conforme sugerida por Geraldi); (6) a desatenção aos estudos linguísticos que ora se operavam (BRITTO, 2002).

No bojo da crítica renovadora, segundo Britto (2002), emergiram duas propostas distintas para oportunizar uma nova abordagem da gramática e do ensino de língua portuguesa na escola: ou se construía uma nova gramática que tivesse um caráter descritivo e adequado à análise da língua em sua realidade constitutiva, ou deixava-se de lado a teoria gramatical, abrindo espaço para a leitura, produção textual e análise linguística (BRITTO, 2002). A primeira proposta ganhou voz em Câmara Jr., Macambira, Lemle, Kato, Perini, entre outros. Britto (2002, p. 151) menciona as razões que davam suporte aos argumentos desse grupo em relação à legitimidade e pertinência do ensino sistemático e regular da gramática (teoria gramatical): "contribui para melhorar a expressão e a capacidade de comunicação (Câmara Jr., Lemle); faz parte da tradição e da cultura nacional (Perini, Câmara Jr., Macambira); é um objeto cientificamente relevante e pode contribuir para a capacitação do raciocínio e da prática científica (Perini, Kato, Lemle)."

A segunda proposta ganhou força principalmente na voz de Franchi e Geraldi, mas também encontrou apoio em Ilari, Possenti, Pécora, entre outros³. Essa (proposta) apontava principalmente na direção de perceber o aluno enquanto sujeito sócio-historicamente constituído que faz uso efetivo de uma língua que também se constitui e se modifica no âmago de relações sócio-históricas. Assim, professores e alunos tornam-se interlocutores. Ainda citando Britto (2002, p. 154), identificam-se três questões centrais nessa proposta, que dizem respeito a concepções de língua e ensino: “(1) A relação do sujeito com a linguagem, destacando-se a importância das noções de trabalho e criatividade; (2) O funcionamento da linguagem e as ações linguísticas; (3) As práticas pedagógicas em uma perspectiva sociointeracionista." Nessa perspectiva, a criatividade pode ser vista como algo inerente à própria atividade linguística.

A rejeição ao ensino da gramática (teoria gramatical) como objeto de ensino preponderante da disciplina de Língua Portuguesa é explicada por Franchi (1987, p. 5) quando diz que a gramática, "mesmo assumindo uma postura descritiva mais moderna, ela sempre resultará de uma redução metodológica que a torna estanque e restritiva. É no uso e na prática da linguagem ela mesma, e não falando dela, que se poderá reencontrar o espaço aberto da liberdade criadora.”.

É nesse momento que surgem, no Brasil, os primeiros ecos de uma nova perspectiva de ensino que se baseia teórica e metodologicamente na compreensão da língua como interação, defendida por Bakhtin e Vygotsky. Freitas (1994) aponta que o discurso encetado por esses teóricos veio ao encontro de uma necessidade presente no meio educacional de se repensar o ensino de língua portuguesa. $\mathrm{O}$ aluno, sob essa perspectiva, é entendido como um sujeito sócio-historicamente situado em um dado contexto, contexto esse no qual a escola também se insere.

\footnotetext{
${ }^{3}$ Britto (2002) sinaliza a influência de uma "escola da Unicamp" no que tange a concepção de linguagem e suas implicações metodológicas para o ensino da língua. Dessa escola faziam parte nomes como: Franchi, Osakabe, Ilari, Pécora, Geraldi, Possenti, Silva et alii e Coudry.
} 
É dessa época a obra O texto na sala de aula, organizada por Geraldi (1984), a qual despontou como guia para redefinir a leitura e a produção de textual no contexto escolar e, logo, a disciplina de Língua Portuguesa. Nela, Geraldi reflete sobre o impositivo de se rever a abordagem tradicional da língua, a qual se apoiava sobre: uma leitura mecânica de textos muitas vezes descontextualizados para o leitor; a escrita sem planejamento prévio; o ensino preponderante da nomenclatura, descrição e classificação gramatical; o ensino de literatura realizado a partir da biografia de autores e listas de obras de referência; a artificialidade do contexto de aplicação da língua em produções textuais que apenas se destinavam a ser lidas (e avaliadas) pelo professor.

O autor assinala a relação intrínseca e necessária entre leitura e produção textual, ressalta a importância de uma abordagem centralizada na noção de interlocução, a pertinência da prática de análise linguística e a necessidade de se redefinir a avaliação da produção textual do aluno, bem como a retomada dessa produção pelo aluno nas aulas de análise linguística. Assim, Geraldi propõe o texto como objeto legítimo e imprescindível nas aulas de Língua Portuguesa.

Em 1991, Geraldi publica Portos de passagem. No livro, dividido em três capítulos - Linguagem e trabalho linguístico, Identidades e especificidades do ensino de língua, e no espaço do trabalho discursivo, alternativas - Geraldi (2002) ratifica: (1) a importância do trabalho com o texto na sala de aula no âmbito das atividades de leitura, produção textual e análise linguística; (2) a pertinência de se focalizar a linguagem a partir do processo interlocutivo, "espaço de produção de linguagem e de constituição de sujeitos." (GERALDI, 2002, p. 5); (3) o caráter sócio-histórico da linguagem, dos sujeitos e da interação.

Ainda, o autor esclarece o caráter das ações linguísticas do sujeito e das atividades linguísticas que ele realiza. Geraldi (2002, p. 26) menciona que "nas ações que se fazem com a linguagem se presentificam ações sobre a linguagem e da linguagem.”, fenômenos esses concomitantes. Qualquer tipo de ação linguística envolve a realização de atividades linguísticas, epilinguísticas e metalinguísticas, as quais representam níveis distintos de reflexão.

Os conceitos de atividade epilinguística e atividade metalinguística remetem a um conjunto de atividades que tomam como objeto o fato de a linguagem poder remeter a si própria, pois, como esclarece Geraldi (2002, p. 189 -190), "com a linguagem não só falamos sobre o mundo ou sobre nossa relação com as coisas, mas também falamos sobre como falamos".

Se, ao falar de atividades linguísticas, remete-se ao uso que os sujeitos fazem da língua no contexto da interação verbal, envolvendo a construção e reconstrução dos textos que se mostrem adequados à mediação dessa interação, conforme objetivos discursivos específicos; quando nos referimos a atividades epilinguísticas, referimo-nos àquelas atividades centradas não só no emprego dos diversos recursos linguísticos em uma dada situação interacional, mas também nos diferentes aspectos da própria interação. Geraldi (2002) pontua, ainda, que ao pensar as atividades epilinguísticas, deve-se entendê-las como aquelas em que, de forma consciente ou não, ao tomar-se as expressões da língua como objeto de estudo, desloca-se o foco de análise do tratamento do tema, para os recursos expressivos mobilizados pelos interlocutores.

Franchi (1987, p. 41-42), ao falar de atividade epilinguística, esclarece que:

[...] Por um lado, ela se liga à atividade linguística, à produção e à compreensão do texto, na medida em que cria as condições para o desenvolvimento sintático dos alunos: nem sempre se trata de "aprender" novas formas de construção e transformação das expressões; muitas vezes se trata de tornar operacional e ativo um sistema a que o aluno já teve acesso fora da escola, em suas atividades linguísticas comuns. Mas por outro lado, essa atividade é que abre as portas para um trabalho inteligente de sistematização gramatical. Porque é somente sobre fatos relevantes de sua língua (relevantes=carregados de significação) que o aluno de gramática pode fazer hipóteses sobre a natureza da linguagem e o caráter sistemático das construções linguísticas, e pode um dia falar da linguagem, descrevê-la em um quadro nocional intuitivo ou teórico. Uma atividade metalinguística. 
De fato, Franchi (1987) deixa claro que pouco interessa ao aluno construir um conhecimento de ordem notacional, o qual tradicionalmente norteou o ensino da Língua Portuguesa, e que era centrado na aquisição de uma "nomenclatura gramatical" e de conceitos sobre o sistema da língua; todavia, é de fundamental importância possibilitar que os alunos desenvolvam a capacidade de operar sobre a linguagem, e, através dela, sobre seus próprios textos, revendo-os e adaptando-os (refacção textual), a partir da manipulação de um amplo repertório de formas linguísticas que a língua disponibiliza para o emprego em cada situação específica de uso (FRANCHI, 1987).

No que tange às atividades metalinguísticas, pode-se concebê-las como aquelas em que se usa a língua para a análise da própria língua, a partir do desenvolvimento de uma metalinguagem apropriada, buscando explicitar sua estrutura, constituição e funcionamento. Nesse caso, a língua é o próprio objeto de estudo. Franchi (1987) e Britto (2002) apontam que a atividade linguística e a epilinguística devem anteceder as atividades metaliguísticas, para que estas não careçam de sentido.

O entrelaçamento de atividades linguísticas, epilinguísticas e metalinguísticas na tecitura que envolve a prática da leitura/escuta, produção e refacção de textos e análise linguística aliou-se à percepção do gênero para balizar uma nova abordagem metodológica do texto. Essa abordagem era, tradicionalmente, norteada pelo trinômio narração, descrição e dissertação, correspondente à tipologia clássica da "redação escolar", a qual registrava o artificialismo de textos produzidos para a escola, para o professor. Ou seja, a produção da "redação escolar" envolvia a produção de textos que não tinham, fora dos muros da escola, existência real, uma vez que não permeavam interações reais no âmbito das diversas esferas sociais.

Geraldi (2002, p. 136) estabelece uma diferença básica entre produção de textos e redação quando afirma que: "nesta, produzem-se textos para a escola; naquela produzem-se textos na escola." ${ }^{4}$. A produção de textos na escola, norteada pela relação interlocutiva, portanto, a produção de textos efetivamente direcionados a um interlocutor concreto, ao qual se deseja dizer alguma coisa, no âmbito de uma dada interação, vincula-se estreitamente à noção de gêneros do discurso conforme apontada por Bakhtin (2003), uma vez que todo enunciado, ou seja, texto na condição de enunciado, reflete

as condições específicas e as finalidades de cada referido campo [da atividade humana] não só por seu conteúdo (temático) e pelo estilo da linguagem, ou seja, pela seleção de recursos lexicais, fraseológicos e gramaticais da língua mas, acima de tudo por sua construção composicional. Todos esses três elementos - o conteúdo temático, o estilo, a construção composicional - estão indissoluvelmente ligados no todo do enunciado [texto na sua condição de enunciado] e são igualmente determinados pela especificidade de um determinado campo da comunicação. (BAKHTIN, 2003b, p. 261).

Como aponta Britto (2002), é inegável a influência do pensamento de Geraldi tanto nos propostas curriculares estaduais, quanto nos PCN, sinalizando na direção de uma prática centrada no trinômio: leitura, produção de textos e análise linguística, que contemple tanto a dimensão oral quanto a dimensão escrita, bem como as diferentes variantes do português. Segundo Geraldi (2002), a produção de texto abre espaço à subjetividade, é o lugar em que o sujeito se compromete com suas palavras. Estabelecendo uma ponte com o pensamento bakhtiniano, pode-se compreender a produção textual como o lugar em que o sujeito revela a sua apreensão de mundo e se posiciona perante seu(s) interlocutor(es). A leitura representa "o espaço possível de respostas, de novas interpretações, de outros saberes que, confrontados com os seus, podem permitir novas descobertas." (BRITTO, 2002, p. 163). As descobertas se dão no confronto, no embate entre a visão de mundo que o leitor (aluno) tem, os já-ditos que atravessam sua realidade, e aquilo que o texto, como enunciado, deixa transparecer. Por fim, a prática da análise linguística constitui a oportunidade da construção de um conhecimento adquirido no contato direto com o texto, na busca ou

\footnotetext{
${ }^{4}$ É importante assinalar que a noção de texto tomada por Geraldi (2002) aproxima-se da noção de enunciado de Bakhtin (2003), afastando-se da noção de texto tradicionalmente acolhida pela escola. Os conceitos de enunciado e de texto na condição de enunciado, em Bakhtin, serão discutidos ao longo do capítulo 2 .
} 
percepção de "recursos expressivos e processos de argumentação que se constituem na dinâmica da atividade linguística." (BRITTO, 2002, p. 164).

Uma prática centrada na apreensão sócio-histórica da língua implica pensar a língua em uso, partindo-se do texto para se chegar ao texto. Essa reflexão coaduna com o que diz Petitjean (1998) sobre o ensino de línguas (o autor fala especificamente do caso do ensino do francês, mas acreditamos que a mesma reflexão possa ser aplicada a qualquer língua), em que o desenvolvimento de competências linguísticas sobrepõe-se ao ensino do conhecimento. Essa perspectiva de trabalho no ensino de línguas toma corpo na noção do que Halté (1998) denomina de elaboração didática.

Se por um lado, nas palavras de Chevallard (1998, p.16, tradução nossa), o conceito de transposição didática associa-se à "passagem do saber sábio [conhecimento científico] ao saber ensinado [conhecimento ensinado], e igualmente à distância eventual, obrigatória que os separa, dá testemunho desse questionamento necessário, ao mesmo tempo em que se converte em sua primeira ferramenta." ${ }^{5}$; por outro, o conceito de elaboração didática está relacionado, primordialmente, à construção de competências linguísticas, e é a serviço destas que os conhecimentos são ensinados, além disso, os conteúdos ensinados não se reduzem aos conhecimentos científicos que foram transpostos, pois tais conteúdos refratam as "práticas sociais de referência", ou seja, os usos sociais efetivos que se faz da língua no contexto das diferentes interações que se efetivam no âmbito das esferas da atividade humana. Isso inclui perceber que os usos sociais da língua têm uma dimensão extraescolar e implica agregar à percepção de transposição didática, o conceito de representação e de contrato didático.

Embutidas no primeiro conceito estão as atividades sócio-cognitivas e discursivas através das quais o sujeito "categoriza e interpreta os objetos do mundo e as representações, como os produtos do pensamento comum, tal como se materializa nas crenças, nos discursos e nos comportamentos dos indivíduos.”, bem como nas "práticas heterogêneas de socialização" - família, escolaridade anterior, mídia, etc... (PETITJEAN, 1998, p. 21). Os professores, apesar de compartilharem com os alunos essas fontes de opinião, ressignificam-nas a partir de suas próprias práticas culturais, ou, numa perspectiva bakhtiniana, a partir de seu horizonte axiológico. Tanto as representações dos alunos, quanto as dos professores, ancoram o quadro interpretativo que determina os modos através dos quais os alunos constroem saberes e através dos quais o professor toma decisões durante a ação pedagógica.

O segundo conceito (de contrato didático) está, no dizer de Petitjean (1998, p.24), "relacionado com o lugar que cada ator tem diante do conhecimento ensinado e das atividades no interior do sistema didático, e com a base de assimetria constituída entre mestre e alunos.”. O contrato didático está na base da compreensão dos rituais que regem a relação professor-aluno e aluno-aluno, contribuindo para a atribuição de papéis sociais, e, portanto, é determinante para legitimação dos discursos que povoam a sala de aula.

Halté (1998, p. 14) assinala que o trabalho com o texto (tomado, em nosso contexto, como objeto de ensino da disciplina de Língua Portuguesa) na sala de aula envolve "colocar em circulação, solidariamente, uma especificidade de escritura, um modelo de prática social e um tipo de conhecimento específico.”. Trabalhar o texto pressupõe ir além dos conhecimentos científicos envolvendo, ao mesmo tempo, conhecimentos de todos os tipos. Para Halté (1998, p. 15), "na prática de sala de aula, o conhecimento científico, a prática social de referência, a especialidade e o conhecimento geral são literalmente sincretizados.”.

Por prática social de referência, Halté (1998) alude a uma noção elaborada por Martinand (1985) que diz respeito às atividades que se operam na escola tomando como referência aquelas que se efetivam na sociedade, levando em conta não um sujeito visto de forma particular, mas um conjunto de sujeitos de um determinado setor social. Halté (1998) usa o termo "especialidade" para se referir a "os conhecimentos

\footnotetext{
Original em espanhol: “[...] al paso del saber sábio al saber enseñado, y por lo tanto a la distancia eventual, obligatoria que los separa, da testimonio de ese cuestionamiento necesario, al tiempo que se convierte en su primera herramienta.”.
} 
especializados, dificilmente objetiváveis, muito personalizados [...]. As instituições que os portam não são reconhecidas pela sociedade que não lhes atribui o direito de 'ditar a cultura num referido campo.” (Halté, 1998, p. 10). Já por conhecimento geral, refere-se a conhecimentos difusos que geralmente estão alijados do processo de ensino, são conhecimentos que o aluno já tem em sua prática.

Assim, o tratamento metalinguístico dado pelo ensino tradicional à gramática da língua portuguesa, ensinada como um objeto fechado em si mesmo, de forma fragmentada e descolada do uso real da língua, aproxima-se da transposição. Entretanto, o trabalho com o texto, no âmbito de atividades de leitura/escuta, produção textual e análise linguística, conforme proposto por Geraldi (2002), só pode efetivar-se na percepção de elaboração didática, pois pressupõe exatamente essa sincretização da qual falávamos anteriormente.

Assim sendo, podemos afirmar que se a transposição didática ancora a reificação dos textos, a elaboração didática ancora um projeto de leitura/escuta e produção de textos assumidos por seus autores, em que "estes, para produzirem, precisam voltar-se para a sua própria experiência (real ou imaginária) para dela falarem: buscam inspirar-se nela para daí extrair o que dizer. E ao dizê-lo, desvelam as categorias (ou sistemas de referência) em que interpretam estas experiências, suas vidas." (GERALDI, 2002, p. 170-171).

Dessa forma, como aponta Viana (2004), a construção do conhecimento no contexto do ensinoaprendizagem de língua materna, sob a perspectiva da elaboração didática, está firmemente imbricada às práticas de produção e refacção de textos, de leitura e de análise linguística, uma vez que essas práticas permitem agenciar conhecimentos através de atividades epilinguísticas que balizam o ato discursivo. O objetivo de uma elaboração didática é mobilizar a construção e a emergência de um "saber fazer" - savoir faire - um saber escrever, reescrever, ler, falar, ouvir, compreender.

De uma metodologia aplicacionista (preconizada pela transposição didática) passamos a uma metodologia implicacionista, definida por Halté (1998, p. 22) com base em "uma didática globalmente praxiológica". A emergência desse saber-fazer sobre a língua, através da língua e na língua só pode ser resultado da reflexão contínua sobre os textos que circulam nas diversas esferas da comunicação humana. Não sobre textos artificiais, mas sobre aqueles que constituem resultado efetivo de interações significativas entre diversos sujeitos histórica e socialmente situados, textos estes produzidos, lidos e interpretados, conscientemente, ou não, através da baliza do gênero.

Maieski (2005) que, em sua pesquisa de mestrado, trabalhou a elaboração didática para a prática de produção textual do gênero artigo assinado associada à leitura e análise linguística em uma turma de terceiro ciclo de uma escola da rede pública oficial de ensino do município de Nova Trento, afirma que a principal contribuição de sua pesquisa talvez tenha sido demonstrar, justamente, que a prática de produção textual não se pode efetivar de forma isolada e de que "O gênero [...] é o elemento chave que pode balizar as atividades de elaboração didática do professor nessas práticas sociais de uso da linguagem no dia-a-dia das aulas de Língua Portuguesa.” (MAIESKI, 2005, p. 207).

Igualmente, Bussarello (2004), que desenvolveu seu projeto de pesquisa de mestrado contemplando a elaboração didática para a prática de produção textual do gênero crônica, lembra que a elaboração didática por ele desenvolvida para dar conta, em contexto de sala de aula, da produção de textos do gênero crônica, não pode nem deve ser tomada à conta de uma receita de bolo. De fato, esse é um ponto central na noção de elaboração didática, pois cada elaboração ou conjunto de elaborações refere-se a um contexto específico de aplicação, delineado pelos professores, pelos alunos e pelo gênero trabalhado, cada qual com suas especificidades. É claro que a elaboração exige uma etapa de planejamento e o conhecimento prévio, por parte do professor, das especificidades do gênero e da interação, dos alunos e da comunidade, mas a elaboração só se efetivará, realmente, na sala de aula. 


\section{A ELABORAÇÃo DIDÁTICA DOS GÊNEROS DO DISCURSO}

Como mencionado anteriormente, a transposição didática dos conteúdos de ensino de Língua Portuguesa está fortemente atrelada à transposição do conhecimento científico para a sala de aula, onde ele (o conhecimento científico) surge descaracterizado e com forte conotação classificatória. Observemos o resumo abaixo, fornecido por licenciados em Letras para alunos de uma turma da $6^{a}$. série do Ensino Fundamental:

R1-2004 - Definições de textos narrativos, descritivos e dissertativos

TEXTO NARRATIVO: contar uma história

"Relato de um enredo imaginário ou não, situado num tempo e num lugar determinados, envolvendo uma ou mais personagens" (AMARAL, 2000, p.24)

Exemplos de textos narrativos a serem identificados pelos alunos: romances, contos, novelas, poemas épicos, crônicas, filmes, fábulas...

TEXTO DESCRITIVO: retrato escrito

“Ato ou efeito de descrever. Exposição circunstanciada que se faz falando ou escrevendo" (AURÉLIO, 1985 , p. 150). Apresenta características de alguém ou de algo, percebidas a partir dos cinco sentido."(AMARAL, 2000, p.496).

Exemplos de textos descritivos a serem identificados pelos alunos: fotografias, diálogos ou textos descritivos, figuras, poemas, receitas e bolo, contratos de locação de imóvel,...

TEXTO DISSERTATIVO: Defender uma opinião. Expor idéias sobre um assunto, debater um tema.

Defender uma opinião com argumentos coerentes e bem situados é o aspecto mais importante do texto dissertativo. Além da argumentação articulada, a dissertação deve apresentar também uma linguagem clara e uma estruturação lógica (com introdução, desenvolvimento e conclusão) (AMARAL, 2000, p. 494).

Exemplos de textos dissertativos a serem identificados pelos alunos: resenhas, artigos, redações, entrevistas, críticas jornalísticas, comentários...

Um texto dissertativo ou narrativo pode conter uma descrição, mas não pode haver dissertação em uma narrativa.

Como se depreende da leitura do resumo fornecido aos alunos, sua elaboração foi norteada pela noção de texto-sistema apoiada sobre a percepção de tipologia escolar: narração, descrição e dissertação; os quais são relacionados, respectivamente, às funções de: contar uma história; fornecer um retrato escrito; defender uma opinião, expor ideias sobre um assunto e debater um tema. A cada tipo de texto, os acadêmicos associam exemplos de textos classificados sob a baliza daquele tipo. Assim, os exemplos de textos descritivos reúnem: fotografias, diálogos, figuras, poemas, receitas de bolo, contratos de locação de imóveis, entre outros. Essa associação evidencia o caráter redutor da classificação de textos a partir da tipologia escolar clássica. Como poderíamos pensar em um diálogo como exemplo de texto descritivo? Há mesmo diálogos que não são sequer atravessados por essa sequência; o mesmo ocorre com os poemas. Retomamos, ainda, a questão da crônica, comentada no capítulo anterior. Se ao escrever uma crônica, ainda que nesta predominem sequências narrativas, o autor está, na verdade, materializando sua opinião a respeito de uma determinada questão, apresentá-la como narrativa, parece paradoxal, encobrindo a percepção do posicionamento axiológico do cronista. Todavia, entendemos como importante assinalar que os acadêmicos de certa maneira percebem o caráter abstrato e redutor da classificação em tipologias textuais, ou seja, percebem que narração, dissertação e descrição constituem esquemas abstratos que se atualizam em textos de um dado gênero. 
A última observação contida no material torna essa questão mais evidente. Ao dizer que "Um texto dissertativo ou narrativo pode conter uma descrição [...]” revela-se a crença na possibilidade de existência de textos exclusivamente descritivos, o que, como aponta Furlanetto (2002), parece incoerente. De fato, ainda que se possa falar que, por exemplo, em um romance, prevalecem sequências narrativas, não se pode afirmar que no romance não haja sequências dissertativas. "Os textos não são prototipicamente descritivos, narrativos ou dissertativos. Antes de usarem essas formas sequenciais, eles são outra coisa: são manifestações de discursos." (FURLANETTO, 2002, p.85).

Quando se pensa em figuras ou fotografias, a questão se torna ainda mais complicada, porque a noção de tipologia escolar não parece apropriada para compreendê-las. De certa forma, a percepção de que a noção de narração, dissertação e descrição não é suficiente para compreender a enorme variedade de textos que produzimos fica clara, quando os acadêmicos migram das tipologias para os gêneros, os quais, entretanto, buscam agrupar pela baliza dos primeiros, a partir da percepção de texto-sistema privilegiada na grade 1998/2.

Vejamos mais um exemplo que retrata a transposição didática dos conteúdos de ensino para a sala de aula. Em R3-2005, na segunda aula, é explicada aos alunos a organização de um jornal e a distinção, ou a classificação, de diferentes gêneros da esfera jornalística. A apresentação da distinção entre os gêneros se dá a partir da apresentação de material fotocopiado, retirado do livro de José Marques de Melo, $A$ opinião do jornalismo brasileiro, que reproduzimos parcialmente a seguir. Notamos que, aqui, o conhecimento é diretamente transposto pelo professor, vindo a resultar em uma lista de gêneros que, em seguida, são definidos. Essa transposição parece-nos pouco efetiva e, como aponta Petitjean (1998), favorece o predomínio do tratamento epistemológico dos conhecimentos escolares (provenientes de conhecimentos científicos) em detrimento de uma prática social e de uma abordagem praxiológica:

\title{
R3-2005 \\ OS GÊNEROS JORNALÍSTICOS
}

\author{
Jornalismo informativo \\ 1 - Notícia \\ 2 - Nota \\ 3 - Reportagem \\ 4 - Entrevista \\ Jornalismo opinativo \\ $5-$ Editorial \\ 6 - Comentário \\ $7-$ Artigo \\ 8 - Resenha \\ 9 - Coluna \\ 10 - Crônica \\ 11 - Caricatura \\ 12 - Carta
}

Notícia: expõe fatos ocorridos, respondendo às perguntas: Quem? O quê? Quando? Onde? Como? Por quê?

Nota: também expõe fatos, mas aqueles que ainda estão em processo de configuração.

$[\cdots]$

Carta: recursos dos leitores para expressar sua opinião no jornal.

(Anexo Plano de Aula III)

A análise do material didático usado pelos acadêmicos permite entrever que esse é assinalado pelo caráter superficial da diferenciação que estabelece entre os diversos gêneros, diferenciação essa fundamentada, sobretudo, na atribuição de funções aos gêneros no âmbito da esfera jornalística. No dizer de Petitjean (1998), isso implica dar aos alunos uma visão rígida de noções/conceitos, deixando de lado a complexificação e reformulação resultantes das interações em sala de aula. 
Este é o único contato que os alunos terão com a maior parte dos gêneros mencionados no material. No caso da notícia, dos classificados e da entrevista, há uma aula dirigida à abordagem de cada gênero. Vejamos o caso da entrevista.

Não há efetivamente uma elaboração didática do gênero entrevista, nem parece haver, por parte dos acadêmicos, a compreensão de que a entrevista publicada em jornal é, na verdade, uma reenunciação da entrevista face a face, em que ocorre um enquadramento do discurso do entrevistado, balizado pelo horizonte apreciativo do jornalista e do jornal (SILVA, 2007). A atividade proposta pelos acadêmicos era a seguinte: um aluno assumia o papel de entrevistador e o outro de entrevistado, cabia ao primeiro entrevistar o segundo. Ao fazê-lo, os alunos podiam representar eles mesmos, ou um terceiro (um outro, real ou imaginário). A atividade proposta não remete à entrevista impressa no jornal, mas à entrevista face a face; que, por sua vez, constitui um gênero oral, que é assinalado por particularidades estilísticas, composicionais e temáticas que não foram sequer ventiladas.

Traçamos aqui raciocínio semelhante ao traçado por Geraldi (2002). A nosso ver, uma questão fundamental na análise das atividades sugeridas em R3-2005 é: para que se lê o que se lê (se escreve o que se escreve, se fala o que se fala) se o que se lê (o que se escreve, o que se fala) na verdade não importa?; importa, sim, reconhecer estruturas; as quais, uma vez obedecidas, cumpriram sua função de ser, em si mesmas, estruturas. É o que acontece com a notícia maluca e com a manchete maluca, que não poderiam ter existência concreta na esfera jornalística. A esta questão junte-se outra tão fundamental quanto a primeira: para que se produz o que se produz? As atividades são sugeridas aos alunos sem que se apontem objetivos, sem que haja um porquê; os acadêmicos falaram em entrevistas jornalísticas, mas em nenhum momento explicitou-se a vinculação entre a atividade proposta em sala de aula e o que efetivamente ocorre na esfera jornalística. Retomamos Geraldi (2002, p. 170), que assinala que o 'remédio pedagógico' [para fugir ao artificialismo das práticas pedagógicas] tem sido criar motivações [balas, doces, prêmios, o lúdico] que, por sua exterioridade, nada mais fazem do que ancorar pelos lados uma legitimidade que não se põe sob suspeita, mas rui sobre seus pés de barro.”. Acreditamos ainda, conforme as observações apontadas por Rodrigues (2008), que o fato de destinar uma aula ao trabalho com cada gênero, o que implica uma elaboração didática por gênero, é insuficiente para que se recubram todas as particularidades do gênero e ainda para que, em cada caso, conjugue-se leitura-estudo do texto, produção textual e análise linguística.

Vejamos, por fim, um último exemplo do trabalho com os gêneros do discurso desenvolvido sob a perspectiva da transposição didática dos conteúdos de ensino. Neste exemplo (extraído de R2-2005), constituído por um trecho de uma das atividades propostas pelos acadêmicos e das respostas dadas por dois alunos, fica muito clara a preocupação em elaborar um conhecimento que possa ser aferido e quantificado:

Exercício

[… 1.O que são onomatopéias?

Resposta 1 - São sons que saem quando batemos a porta bate: bou!, sono: z,z,z!

Resposta 2 - São signos convencionais que representam ou imitam um som por meio de caracteres alfabéticos.

3.Cite 3 exemplos de balões das hqs.

Resposta 1 - Cochixo, legenda tradicional, Balão duplo

Resposta 2 - Balões de fala, balões de pensamento,

[...] 5. As histórias em quadrinho trazem algum tipo de informação?

Resposta $1-$ Sim.

Resposta $2-$ Sim.

6. Qual a diferença entre língua falada e escrita?

Resposta 1 - A língua falada evolui a escrita não.

Resposta 2 - A língua falada é uma língua mais espontânea você fala gírias, a língua escrita é uma língua mais certa você não pode escrever gírias tem que ser uma coisa mais normal.

7. Qual a diferença entre as HQs e outros textos? 
Resposta 1 - Que as hqs tem a língua expontânea e os outros textos tem a língua formal.

Resposta $2-$

8. De tudo que foi feito o que você aprendeu com as histórias em quadrinho?

Resposta $1-$

Resposta 2 - Cada fala da história em quadrinho tem seu balão.

Analisando as respostas dadas pelos alunos às perguntas elaboradas pelos acadêmicos, percebemos: (1) a atenção dada a uma metalinguagem centralizada na ideia de definir e classificar, metalinguagem essa que os alunos internalizam; (2) a dificuldade dos alunos em relatarem o que aprenderam; (3) a influência da voz dos acadêmicos na construção de uma "diferenciação" entre oralidade e escrita. Essa influência pode ser percebida na leitura do excerto abaixo, reproduzido a partir de um resumo fornecido pelos acadêmicos aos alunos, em que se evidencia a dificuldade, dos próprios acadêmicos, em diferenciar oralidade e escrita, apresentadas de forma dicotômica:

$\mathrm{R} 2-2005$

[...] DIFERENÇAS ENTRE LÍNGUA E ORALIDADE

A língua pode ser falada ou escrita.

A língua falada é viva e atual. Ela é mais comunicativa e insinuantes, porque as palavras são fortemente subsidiadas pelo sonoridade e inflexões da voz, pelo jogo fisionômico e a gesticulação (mímica), recursos estes que a língua escrita desconhece.

A língua escrita é totalmente artificial, exige treinamento, memorização, exercícios, e obedece a regras fixas, de tendência conservadora, além de ser uma falsa representação da língua falada. [...] (Anexos)

Ainda que predomine a transposição didática da noção de gênero do discurso nas atividades propostas pelos acadêmicos, o relato das atividades de estágio de alguns relatórios de estágio supervisionado elaborados na vigência da segunda grade estudada, chamaram-nos a atenção exatamente porque nesses casos observa-se um trabalho bastante efetivo e eficiente de elaboração didática da noção de gênero do discurso para a prática de leitura, produção textual e análise linguística. Dentre esses relatórios, realçamos RA3-2008, voltado à elaboração didática da carta do leitor. Nesse caso, percebemos a atenção à sistematização de sequências didáticas conforme sugerem Schneuwly e Dolz (2004) e conforme sugerem as orientações teóricometodológicas adotadas pelo curso de Letras em questão, na vigência da grade 2004/1. Resumimos, no quadro abaixo (Quadro 1), as elaborações didáticas que ocorreram ao longo das oito aulas em que se trabalhou o gênero em RA3-2008.

Seguindo a sequência didática modelar sugerida pelos autores, os acadêmicos dividiram o trabalho em cinco etapas: (1) leitura e interpretação de uma notícia; (2) produção inicial sem que anteriormente sejam levantados aspectos do gênero trabalho, de fato, nesse caso, não se elucidam questões a respeito do gênero trabalhado, nem da situação de interação, solicita-se apenas dos alunos que escrevam um texto se posicionado frente à notícia lida; (3) construção de um conceito sobre o gênero, discussão sobre a situação de interação mediada pelo gênero, sobre o(s) suporte(s) em que circula, sobre a esfera em que se constitui e a leitura de textos do gênero para depreensão de regularidades; (4) módulos destinados à discussão de coesão, coerência e uso de conectores; (5) produção final. Os acadêmicos se distanciam da proposta de sequência didática sugerida pelo grupo de Genebra apenas em dois aspectos: utilizam-se de textos autênticos, e, no momento da primeira produção textual, não esclarecem características da interação que o texto deve mediar, nem o gênero que deve balizar essa produção.

Entendemos que efetivamente houve pesquisa por parte dos acadêmicos em relação às peculiaridades do gênero, ou seja, eles têm o que dizer sobre o gênero. Ainda, depreendemos a existência de uma base teóricometodológica que norteia o trabalho de elaboração didática, o que ajuda os acadêmicos a divisar motivos e organizar estratégias para dizê-lo. Apesar de entendermos que a análise linguística poderia se centralizar nos textos lidos e nos textos produzidos pelos alunos, compreendemos que o trabalho realizado com coesão, coerência e conectivos foi relevante e pertinente, ainda que se tenha por vezes trabalhado no nível da frase. Acreditamos que tanto a dimensão social, quanto a dimensão verbal do gênero receberam atenção, 
entretanto, parece haver pouco espaço para a discussão dos papéis dos interlocutores, não há referências (em nenhum dos dois relatórios) a questões relativas ao público leitor do jornal.

\section{Quadro 1 - Sequência de atividades propostas pelos acadêmicos e relatadas em RA3-2008:}

- Foi apresentada aos alunos em transparência a notícia "Cidade de Miami quer proibir calças de cintura baixa”;

- Interpretação oral do texto recobrindo: o que aconteceu, com quem, quando, onde, como e por que;

- Os acadêmicos pedem aos alunos que se posicionem contra ou a favor do texto da proibição e os argumentos por eles levantados são alinhados no quadro;

- A partir dos argumentos levantados, os acadêmicos pedem aos alunos que escrevam um texto posicionando-se contra ou a favor da proibição;

- Alguns alunos lêem seus textos;

- Análise dos jornais (A Notícia, Diário Catarinense, Jornal de Santa Catarina, Município Dia-a-dia) e das revistas (Veja, Terra, Superinteressante e Capricho), enfatizando: os elementos constitutivos da capa e as seções que compõem o jornal; a diferença entre textos informativos e textos opinativos;

- Os acadêmicos pedem aos alunos que localizem a seção de carta dos leitores e leiam algumas cartas a fim de verificar: - a localização da seção cartas do leitor; - o espaço ou importância que cada um dos veículos impressos atribui a essas cartas; - os títulos que essa seção recebe; - a estrutura dessas cartas (título, assinatura, expressão de despedida, local); - a linguagem empregada (formal ou informal);

- Comparação entre as seções destinadas à publicação das cartas nos jornais e nas revistas;

- Cada aluno recebe fotocópias de duas notas e de duas cartas feitas por leitores sobre cada uma dessas notas: "Quanto ganham os políticos?" e "Como driblar o telemarketing", ambas publicadas na revista Superinteressante;

- Após serem lidas em voz alta, discute-se as intenções que os leitores podem ter ao escrever uma carta (elencam: concordar, discordar, sugerir, solicitar, elogiar - quanto à qualidade ou à forma como o veículo conduziu o assunto, reivindicar, aprofundar o debate, demonstrar indignação, ironizar);

- Os acadêmicos solicitam que os alunos retornem às cartas lidas e identifiquem, em cada caso, a intenção do autor;

- Os acadêmicos debatem com os alunos as seguintes peculiaridades do gênero: poder se referir a qualquer texto publicado no jornal ou na revista; não necessariamente fazer referência a textos publicados naquele veículo (a carta pode tratar de algum assunto que esteja em pauta no momento, de uma data comemorativa ou de uma situação ocorrida); permitir que haja resposta por parte dos envolvidos (redator/ pessoa acusada);

- Os acadêmicos mostram aos alunos modelos de respostas que o Jornal Folha de São Paulo envia aos leitores para justificar o fato de suas cartas não terem sido publicadas.

- Apresentação de dois textos aos alunos para demonstrar exemplos de coerência e incoerência, ressaltando que para que as cartas sejam publicadas pelo jornal/revista, elas devem ser coerentes;

F - Os acadêmicos vinculam coerência e coesão ao uso de conjunções e advérbios;

- Em grande grupo pede-se que os alunos ordenem um parágrafo;

- Os acadêmicos revisam com os alunos o funcionamento das conjunções, apresentando exemplos que ilustrem seu uso.

- $\quad$ • Exercícios de substituição de conjunção da frase por outra que transmita idéia semelhante;

l $\quad$ - Entrega e explicação de material didático contendo "as idéias estabelecidas pelos conectores, com exemplos e possibilidades de substituição sem alteração do sentido”;

- Em seguida os alunos realizam dois jogos (Roleta dos argumentos e Jogo da memória) para exercitar coesão e coerência;

- Atividades de fixação do conteúdo (no nível da frase).

- Leitura e discussão da crônica "Manifesto das cheinhas, roliças e simpatizantes", escrita por Maicon Tenfen e publicada no Jornal de Santa Catarina, em 27/09/2007, para cada aluno;

- Proposta de produção final: cada trio deve reler a crônica e redigir uma carta em nome dos três leitores para o escritor Maicon Tenfen;

- Os acadêmicos os orientam para: perceber os motivos que tenham levado o autor a escrever sobre esse assunto e com aquela abordagem; estabelecer, primeiramente, com que finalidade(s) irão escrever a carta; redigir com clareza, concisão, coerência e coesão.

- Uma vez escrita a primeira versão, ela é corrigida pelos acadêmicos que fazem sugestões para melhoria do texto e solicitam a reescrita.

- As cartas foram encaminhadas ao escritor Maicon Tenfem.

Fonte: Relato de atividades de docência e planos de aula em RA3-2008 - 2008 (SILVEIRA, 2008). 
Em RA2-2008, acreditamos apenas que a situação de produção final poderia ter se aproximado mais de uma situação real de interação, nesse sentido, os textos dos alunos poderiam ser enviados ao jornal como o foram em RA5-2008. Ainda assim, ao se definir um interlocutor para o texto (o escritor Maicon Tenfem), nota-se claramente a orientação dos textos dos alunos para este leitor, a tomada de posição axiológica frente ao texto do outro e a adoção de um estilo informal, com pinceladas de humor, que provavelmente não se revelaria se o destinatário fosse o jornal e não o autor, como se nota no texto transcrito abaixo:

RA3-2008

Olá caro escritor,

Consideramos sua crônica muito interessante, porque essa história de ser magra não leva a nada, o bom mesmo é ser cheinha. Para que ser magra (só pele e osso) se não tem onde pagar, porque se tem uma coisa que os homens gostam mesmo de pegar é uma mulher em forma, que mostre suas curvas.

Não é preciso ser obesa, mas também não é ser anoréxica, e sim estar em forma não deixando de se alimentar com o que gosta. O que adianta você estar perto de uma mesa farta de comida, com doces, pizzas, sanduíches, brigadeiros, etc e não poder comer? Porém não se deve abusar, tem que comer o necessário.

Concordamos com você que isso tudo é culpa da mídia, mas infelizmente a ditadura da magreza já se espalhou pelo mundo inteiro. Há jovens de todo o mundo que querem ser magras e se inspiram em modelos famosas, porque acham que sendo magras irão ser como elas.

Concluímos, você já deve estar cansado e saber que “todo avião tem pneu.”.

(Apêndice)

\section{CONSIDERAÇÕES FINAIS}

A pesquisa apontou a importância de o corpo docente da universidade tomar os relatórios analíticos de estágio supervisionado como objeto de estudo para analisar os movimentos que se efetivam no contexto do curso, a fim de empreender ações didático-pedagógicas que fomentem a reflexão sobre a elaboração didática dos conteúdos de ensino, a qual deverá se efetivar nas salas de aula em que os acadêmicos irão atuar quando docentes.

No que concerne ao trabalho com a tipologia escolar, esse é norteado pela noção de texto-sistema, em que o parágrafo é tomado como unidade de trabalho. A elaboração das atividades didático-pedagógicas visa à transposição de conceitos e de uma estrutura textual. Tais atividades são assinaladas pela artificialidade que marca a produção da redação escolar. As atividades de produção textual são propostas de maneira desvinculada da situação de interação, não se definem interlocutores, os autores não retomam seus textos, ou seja, não é incentivada a refacção dos textos. É reservado pouco espaço para a análise linguística. As atividades de leitura, sempre do texto do outro, geralmente se destinam ao reconhecimento de estruturas "ensinadas". Todo esse quadro apresentado aproxima o trabalho com a tipologia escolar clássica da noção de transposição didática, no qual o principal objetivo da ação pedagógica é a transposição de conhecimentos científicos, tornados ensináveis; no quadro da sala de aula, esses conhecimentos tornam-se mais prescritivos do que descritivos.

No que concerne ao trabalho com gêneros do discurso, observamos que, na vigência da grade 1998/2, nos relatórios de estágio que fazem referência ao trabalho com o gênero, prepondera a preocupação com a identificação de textos dos diversos gêneros de forma a classificá-los a partir de parâmetros fornecidos pelos acadêmicos. Frequentemente foca-se a aquisição de uma notação de ordem metalinguística sobre os gêneros, sem que esses sejam efetivamente alvo de elaboração didática; o trabalho com o gênero é, então, balizado pelas mesmas práticas que se elege no trabalho (metalinguístico) com a gramática e com a narração, descrição e dissertação. Ou seja, como aponta Rojo (2001), as velhas práticas agem parasitando as novas.

Na vigência da grade 2004/1 (à semelhança do que ocorre na grade 1998/2), ainda que muitas vezes os gêneros também não sejam efetivamente alvo de elaboração didática e que ainda sejam, por vezes, entendidos sob o fundo aperceptivo da noção de tipologia escolar clássica, depreendemos em alguns 
relatórios elaborados nesse período a perspectiva de mudanças no que tange à elaboração didática dos gêneros para a prática de leitura/escuta, produção textual e, mais raramente, na prática de análise linguística. Isso se verifica na preocupação em se pesquisar sobre o gênero a ser trabalhado; na busca por oportunizar ao aluno desenvolver um conhecimento procedimental do gênero e na articulação de práticas de leitura e produção textual. Acreditamos, mesmo, que dada a acanhada mudança que efetivamente se materializou na grade curricular do curso a dimensão dos resultados obtidos é bastantante significativa. Coadunando com Rodrigues (2008), o aprofundamento do trabalho com o gênero, quando ocorre, se dá ao longo de várias elaborações didáticas que permitem aprofundar, progressivamente, o conhecimento sobre o gênero e seu domínio, exercitado em atividades de escuta, leitura e produção de texto. A prática de análise linguística, talvez refletindo a precariedade do espaço dedicado a sua discussão na universidade, fica, com raras exceções, alijada deste processo.

\section{REFERÊNCIAS}

ÂNGELO, G. L. de. Revisitando o ensino tradicional de língua portuguesa. 2005. 265f. Tese (doutorado) Instituto de Estudos da Linguagem, UNICAMP, Campinas, 2005.

BAKHTIn, M. M. Problemas da poética de Dostoiérski. Tradução do russo por Paulo Bezerra. 2. ed. rev. Rio de Janeiro: Forense Universitária, 1997[1929].

Questões de literatura e de estética (a Teoria do Romance). Tradução de Aurora F. Bernadini et al.4. ed. São Paulo: Editora da UNESP, 1998 [1975].

Apontamentos. In: Estética da criação verbal. Tradução de Paulo Bezerra. São Paulo: Martins Fontes, 2003a[1975]. p. 369-398.

Os gêneros do discurso. In: Martins Fontes, 2003b[1975]. p. 261-306.

O problema do texto na linguística, na filologia e em outras ciências humanas. In: Estética da criação verbal. Tradução de Paulo Bezerra. São Paulo:

criação verbal. Tradução de Paulo Bezerra. São Paulo: Martins Fontes, 2003c [1975]. p. 307-336.

. Metodologia das ciências humanas. In: Estética da criação verbal. Tradução de Paulo Bezerra. São Paulo: Martins Fontes, 2003d [1975]. p. 393-410.

BRITTO, L. P. L. A sombra do caos: ensino de língua x tradição gramatical. São Paulo: Mercado de Letras, 2002.

BUSSARELLO, J. M.. O ensino/aprendizagem da produção textual escrita na perspectiva dos gêneros do discurso: a crônica. 2004. 361 f. Dissertação (Mestrado em Linguística) - Programa de Pós-Graduação em Linguística, Universidade Federal de Santa Catarina, Florianópolis, 2004.

CHEVALLARD, Y. La transposición didáctica: del saber al saber enseñado. 3. ed. Tradução de Claudia Gilman. Buenos Aires: Aique, 1998.

FRANCHI, C. Criatividade e gramática. Trabalhos em Linguística aplicada, n. 9, p. 5-45, 1987.

FREITAS, M. T. de A. Vygotsky e Bakhtin-Psicologia e Educação: um intertexto. São Paulo: Editora Ática, 1994.

FURLanetTo, M. M. Produzindo textos: gêneros ou tipos? Perspectiva, v. 20, n. 01, p. 77-104, jan/jun. 2002.

GERALDI, J. W. O texto na sala de aula - leitura \& produção. 3. ed. Cascavel: ASSOESTE, 1984.

Portos de Passagem. 4. ed. São Paulo: Martins Fontes, 2002.

HALTÉ, J. L'espace didactique et la transposition. Pratiques. Metz: Siege Social, n. 97-98, jun 1998. Trad. Ana Paula Guedes Pinto, versão preliminar.

MAIESKI, M. N. O gênero do discurso artigo como objeto de ensino-aprendizagem: uma proposta de integração da prática de produção textual à leitura e à análise linguística. 2005. 209 p. Dissertação (Mestrado em 
Linguística) - Programa de Pós-Graduação em Linguística, Universidade Federal de Santa Catarina, Florianópolis, 2005.

PETitjeAn, A. La transposition didactique en français. Pratiques, Metz: Siege Social, nº 97-98, junho, 1998. Trad. Ana Paula Guedes Pinto, versão preliminar.

RODRIGUES, R. H. Pesquisa com os gêneros do discurso na sala de aula: resultados iniciais. Acta Scientiarum: language and culture, v. 30, p. 169-175, 2008.

ROJO, R. Modelização didática e planejamento: duas práticas esquecidas do professor. In: KLEIMAN, A. B. (Org.). A formação do professor. Campinas: Mercado das Letras, 2001. p. 313-335.

SCHNEUWLY, B.; DOLZ, J. et al. Gêneros orais e escritos na escola. Trad. e org. Roxane Rojo e Glaís Sales Cordeiro. Campinas: Mercado das Letras, 2004.

SILVA, N. R. da. O gênero entrevista pingue-pongue: reenunciação, enquadramento e valoração do discurso do outro. 2007. 237 p. Dissertação (Mestrado em Linguística Aplicada) - Programa de Pós-gradução em Linguística, Universidade Federal de Santa Catarina, Florianópolis, 2007.

SILVEIRA, A.P.K. da. O lugar dos gêneros do discurso nos projetos e relatórios de estágio do Curso de Graduação em Letras Inglês/Português da Universidade Regional de Blumenau. 268 f. Dissertação (Mestrado) - Programa de Pós-Graduação em Linguística, Universidade Federal de Santa Catarina, Florianópolis, 2008.

VERMON, S. M. Gêneros do discurso - esse obscuro objeto de desejo: contribuição para uma leitura crítica dos PCNs de Lingua Portuguesa. 2004. 120p. Dissertação (mestrado em Letras) - Curso de Pós-graduação em Letras, Universidade Federal do Paraná, Curitiba, 2004.

VIANA, M. R. A elaboração didática nos documentos oficiais de ensino e na sala de aula da rede municipal de Jaguaruna: um estudo de caso. 2004. 125 p. Dissertação (Mestrado em Linguística) - Programa de PósGraduação em Linguística, Universidade Federal de Santa Catarina, Florianópolis, 2004.

VOLOSHINOV, V. N./ BAKHTIN. M. M. Marxismo e filosofia da linguagem: problemas fundamentais do método sociológico na ciência da linguagem. 11. ed. São Paulo: Hucitec, 2004.

Recebido em 31/o8/2011. Aprovado em 12/12/2011. 